\title{
Nerve sparing clitoroplasty in a rare case of idiopathic clitoromegaly
}

\author{
Abha Rani Kujur, Vijay Joseph, Praveen Chandra \\ Department of Plastic Reconstructive Surgery and Burns, St John's Medical College Hospital, Bengaluru, Karnataka, India \\ Address for correspondence: Dr. Abha Rani Kujur, Department of Plastic Reconstructive Surgery and Burns, St John's Medical College \\ Hospital, Koramangala, Bengaluru - 560 034, Karnataka, India. E-mail: dr.abhakujur@gmail.com
}

\section{ABSTRACT}

Clitoromegaly is an embarrassing condition causing psychological stress, requiring intervention. The goals of clitoroplasty are to achieve normal genital anatomy and to preserve tactile sensation with a satisfactory sexual response. We present a rare case of idiopathic clitoromegaly managed by reduction clitoroplasty, preserving the dorsal neurovascular bundle and extensive network of nerves around the corpora to the glans and the creation of labia minora.

\section{KEY WORDS}

Clitoris; clitoromegaly; clitoroplasty

\section{INTRODUCTION}

clitoral index of $>35 \mathrm{~mm}^{2}$ (length $\times$ width) is called clitoromegaly. ${ }^{[1,2]}$ Idiopathic clitoral enlargement is rare and the data in literature are from case reports.

The nerves and vessels form an extensive network around the end of corporeal bodies with an extensive network of nerves to the glans distally. ${ }^{[3]}$ The contribution of different parts of the clitoral complex to sexual sensitivity, arousal and orgasm is not clear. ${ }^{[4]}$

Optimal sexual function after surgical correction of clitoral hypertrophy requires adequate innervation and vascular supply to the glans clitoris. These goals are accomplished by shortening the corpora cavernosa, while preserving the neurovascular supply to the glans.

\begin{tabular}{|l|l|}
\hline \multicolumn{2}{|c|}{ Access this article online } \\
\hline Quick Response Code: & Website: \\
\hline & www.ijps.org \\
\hline & DoI: \\
\hline
\end{tabular}

Several clitoroplasty methods have been reported, but few describe preservation of dorsal and ventral neurovascular bundles in sexually mature women. We present a case of idiopathic clitoromegaly treated with clitoroplasty, where the dorsal neurovascular bundle was preserved along with the extensive network of nerves around the end of corporeal bodies to the glans.

\section{CASE REPORT}

A 20-year-old female presented with an enlarged clitoris [Figure 1]. She had not sought medical attention so far. There was no history of drug abuse, clitoral irritation or family history. She attained menarche at 13 years of age, with irregular cycle and normal flow. There was no hirsutism, obesity, systemic abnormality or anomaly detected.

This is an open access article distributed under the terms of the Creative Commons Attribution-NonCommercial-ShareAlike 3.0 License, which allows others to remix, tweak, and build upon the work non-commercially, as long as the author is credited and the new creations are licensed under the identical terms.

For reprints contact: reprints@medknow.com

How to cite this article: Kujur AR, Joseph V, Chandra P. Nerve sparing clitoroplasty in a rare case of idiopathic clitoromegaly. Indian J Plast Surg 2016;49:86-90. 
On local examination, her clitoris measured $6 \mathrm{~cm}$ in length and $1 \mathrm{~cm}$ in width with enlarged glans. She had normal labia majora, deficient labia minora a small vaginal introitus and normal urethral opening.

On investigating luteinizing hormone (LH), follicle stimulating hormone (FSH), serum prolactin, serum cortisol and 17-hydroxyprogesterone $(\mathrm{OH}$ Progesterone) were all found within the normal range. Ultrasonography (USG) of the abdomen was normal.

Intersex is a group of conditions where there is a discrepancy between the external genitals and the internal genitals (the testes and ovaries). Our patient had no such findings. She had all female sexual features. She had attained menarche. She did not have any male sexual organ. So, the diagnosis of intersex was excluded.

All investigations were normal and no other anomaly was noted. The patient had all normal sexual physical features of a female. All hormonal assays and investigations done were normal, and it was concluded that there was no other abnormality. So, a diagnosis of idiopathic clitoromegaly was made.

Chromosomal studies can be done in cases where there is a doubt about the diagnosis and also to confirm the diagnosis.

\section{Surgical procedure}

Surgery was done in the lithotomy position. A stay suture was placed on the glans for traction using 4-0 monofilament. Incision was made on the prepuce skin 2-3 $\mathrm{mm}$ proximal and parallel to the corona of the glans, extending $270^{\circ}$ on the dorsolateral surface of the prepuce. The ventral connection of the skin was preserved [Figures 2 and 3].

The skin was retracted over the phallus toward the base to expose Buck's fascia, but the ventral tissue was preserved. Tourniquet was applied to the base using a vascular loop [Figure 4].

Two longitudinal incisions were made on both sides of the phallus, lateral to the dorsal neurovascular bundle through Buck's fascia upto the corpora cavernosa [Figure 5].

The dorsal neurovascular bundle was isolated and lifted off the phallic shaft using a vascular loop [Figure 6]. Ventral urogenital tissue was isolated and secured with a vessel loop, and vessel loop previously placed around the

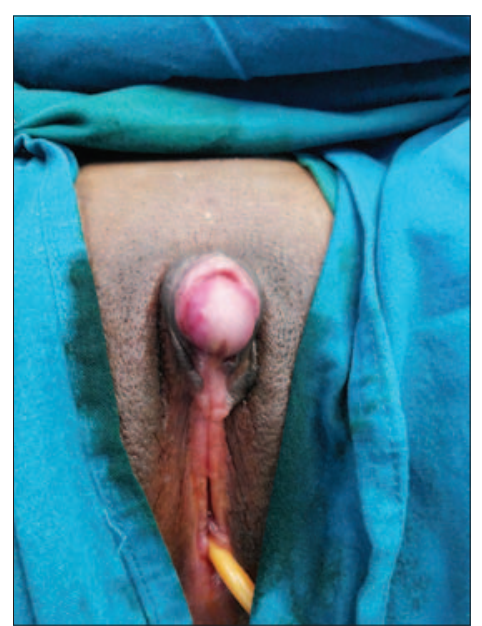

Figure 1: Preoperative image showing enlarged clitoris and glans with deficient labia minora (original)

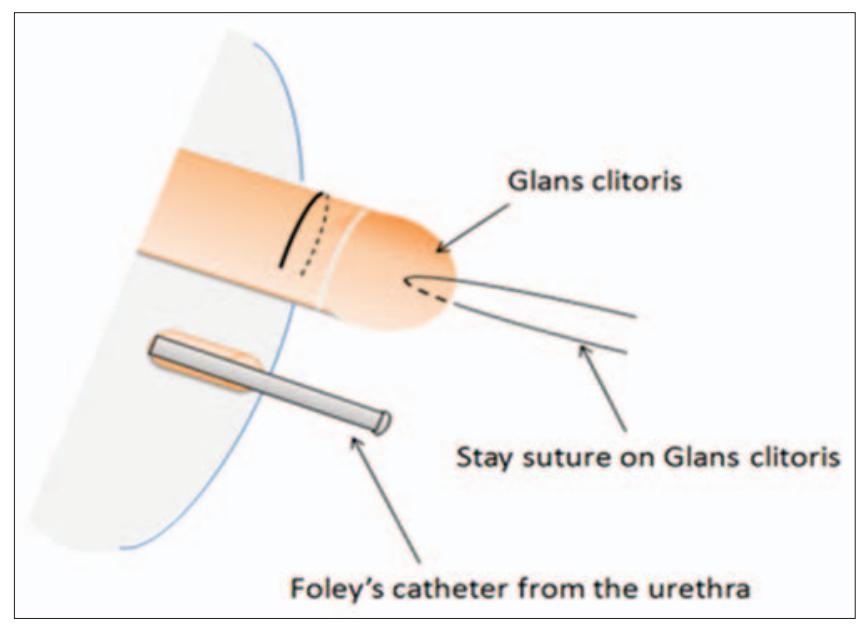

Figure 2: Incision on body of clitoris (original)

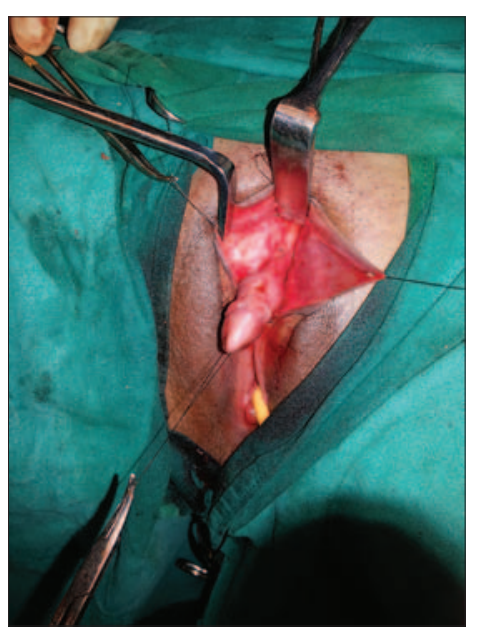

Figure 3: Semicircular skin incision has been given. A stay suture has been placed in the glans clitoris. A Foley catheter exits from the urethra (original)

base of the phallic shaft as a tourniquet was tightened to minimize bleeding. The dissection was carried proximally to the bifurcation of the corpora. The two crura were Indian Journal of Plastic Surgery January-April 2016 Vol 49 Issue 1 
identified, clamped and the mid body of the corpora resected [Figure 7].

The proximal corpora were closed with 4-0 Vicryl for haemostasis. The base of the glans was sutured to the divided proximal corpora with 4-0 Vicryl interrupted sutures. After haemostasis was confirmed, the skin was closed with 4-0 vicryl interrupted sutures to re-approximate the labia minor and the clitoris [Figures 8 and 9].

\section{Histopathological report-normal corporal tissue}

Follow-up: The patient is under follow-up since 1 year after operation. There were no early and late postoperative complications. Sensation was normal and the patient was satisfied with the appearance.

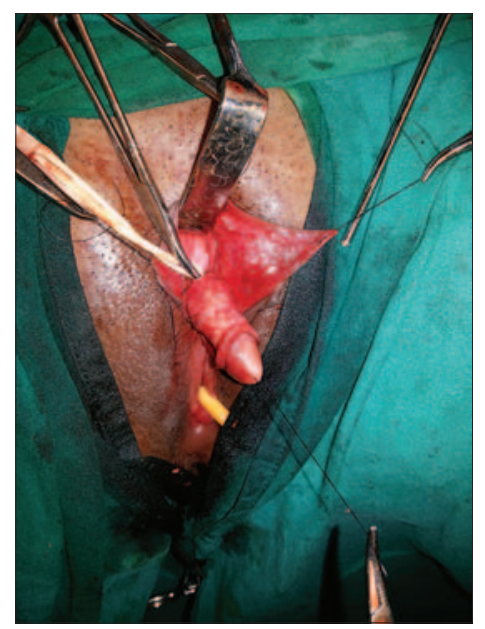

Figure 4: Skin over the clitoral shaft has been reflected to reveal Buck's fascia (original)

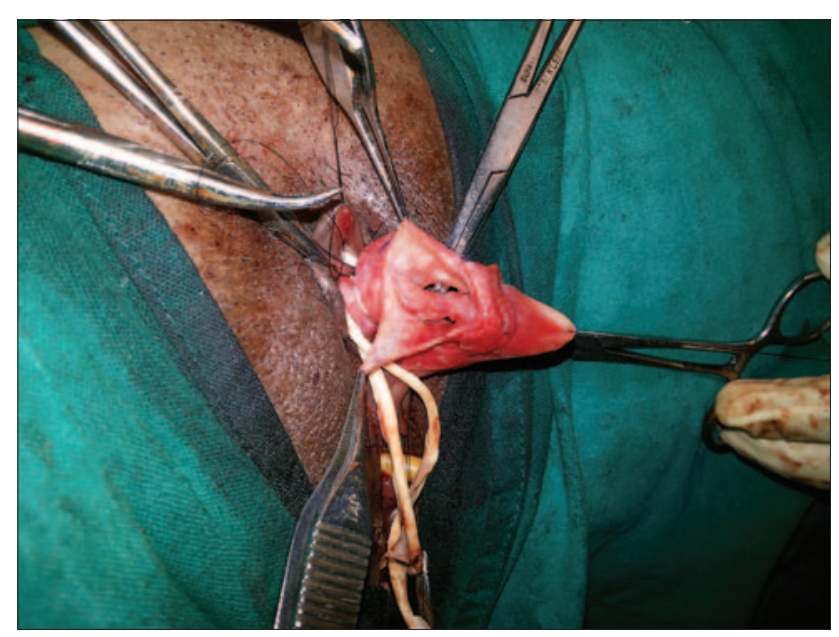

Figure 6: The dorsal neurovascular bundle dissected off the corpora and retracted with vascular loop. A separate vascular loop used as tourniquet to maintain haemostasis at the base of the phallus. The ventral cutaneous pedicle is isolated and reflected downward (original)
Tactile sensation on the clitoris contributes to sexual arousal. By preserving the nerve supply during clitoroplasty, sensation to the clitoris was preserved. This will eventually help the patient in sexual life as the sensation to the clitoris in our patient was preserved [Figure 10].

\section{DISCUSSION}

When a patient presents with clitoromegaly, an etiology should be looked for first. Causes of clitoromegaly can be classified into hormonal, non-hormonal, psuedo-clitoromegaly and idiopathic causes..$^{[5,2]}$

Complete diagnosis can be made by detailed clinical examination and investigations. ${ }^{[1]}$ Patients with clitoromegaly presenting with hirsutism or associated virilising features require a hormonal assay and imaging. It could be due to polycystic ovarian syndrome (PCOS), adrenal or ovarian cause. Patients with PCOS will be

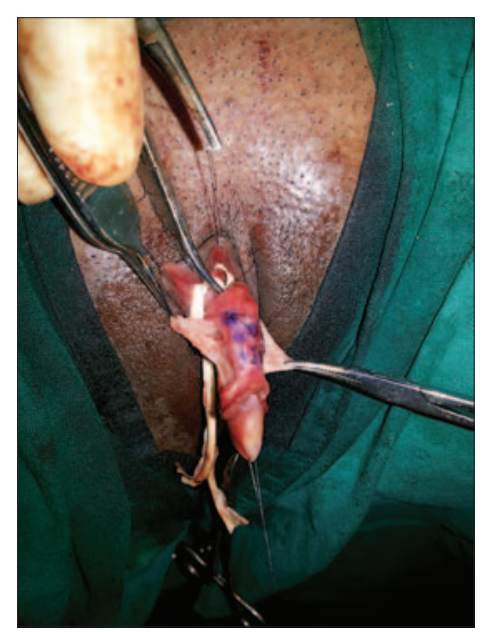

Figure 5: Longitudinal incision has been made to elevate the dorsal neurovascular bundle (original)

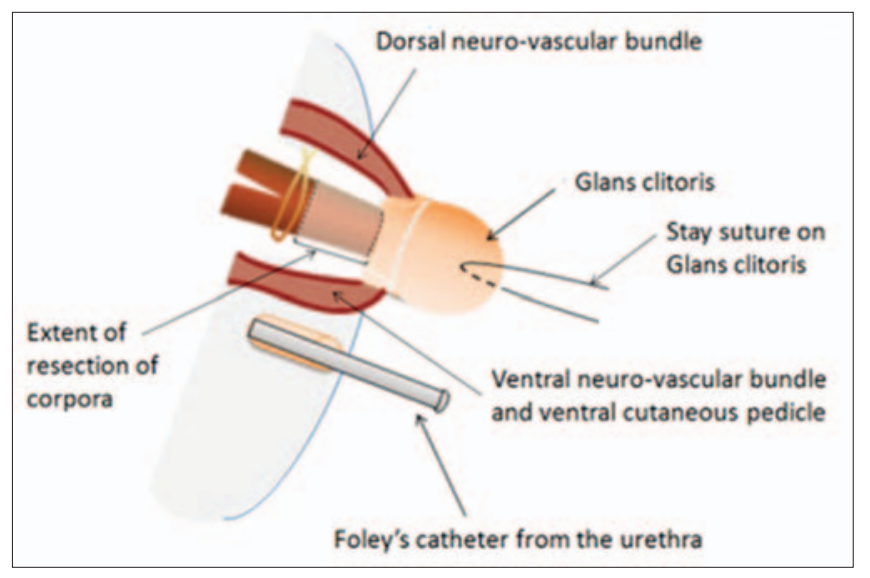

Figure 7: Extent of resection (original) 
obese with abnormal glucose tolerance test (GTT) and insulin resistance. USG will show cysts in ovaries and LH/ FSH $>2$ : 1.Dehydroepiandrosterone (DHEA) sulphate and serum testosterone will be elevated in a patient with ovarian or adrenal cause. Suppression by Dexamethasone suppression test implies adrenal source of clitoromegaly. If there is elevated 17-OH Progesterone level after adrenocorticotropic hormone (ACTH) stimulation, it implies the patient has congenital adrenal hyperplasia. Further magnetic resonance imaging (MRI) may have to be done for any tumour in the ovary or the adrenal glands. If a patient with clitoromegaly does not have hirsutism, then the clitoromegaly can be due to local causes of cysts or tumours. If no local cyst or tumour is found, the clitoromegaly is of idiopathic cause [Figure-11].

In this case, because all investigations were normal, it was concluded to be idiopathic in origin.

Treatment includes medical therapy to treat the underlying cause and surgical clitoroplasty safeguarding the neurovascular pedicles for preservation of sexual arousal function. ${ }^{[2]}$

Knowledge of anatomy is crucial. There is a dorsal neurovascular pedicle from the pudendal nerve ${ }^{[6]}$ along with an extensive network of nerves to the glans. The contribution to different parts of the clitoris to sexual sensitivity, arousal and orgasm remains unclear: ${ }^{[4]}$ Major difference between male and female external genitalia is urethra. ${ }^{[7]}$ Cross-sectional anatomy of the clitoris is same as the penis but has no urethra and corpora sponsiosum [Figure 10]. Surgical methods for correction of clitoral hypertrophy were first described in 1934 by Young. ${ }^{[8]}$

It was understood that the clitoris has a crucial role in the development of female sexuality. This prompted the development of techniques to bury the clitoris..$^{[9]}$ This procedure leads to pain on arousal. Various methods of clitoroplasty with corporal resection and preserving the dorsal neurovascular bundle have been described. ${ }^{[8,9]}$ A surgery, where the all neurovascular bundles to the glans are maintained, is the most acceptable method of clitoroplasty.

\section{CONCLUSION}

Idiopathic clitoromegaly is rare with few case reports. A detailed history and workup is necessary before labeling

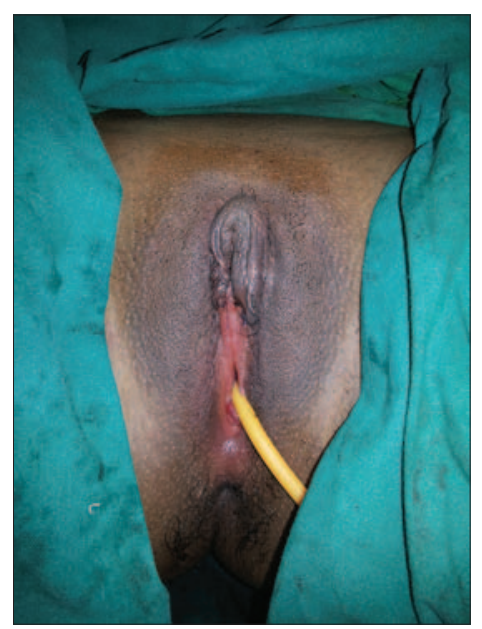

Figure 8: Immediate postoperative image showing Neo Clitoris, Neo labial minora creation (original)

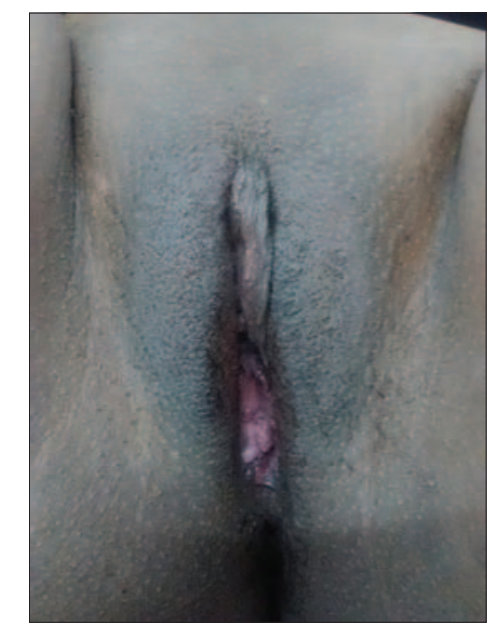

Figure 9: Late postoperative image (original)

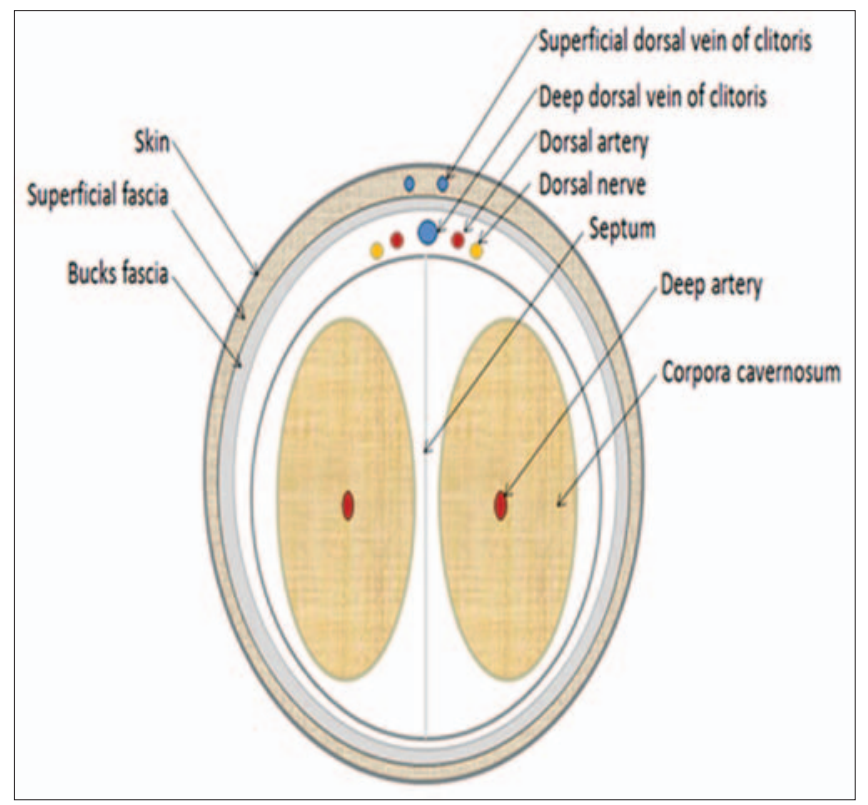

Figure 10: Cross-section of the clitoris (original) 


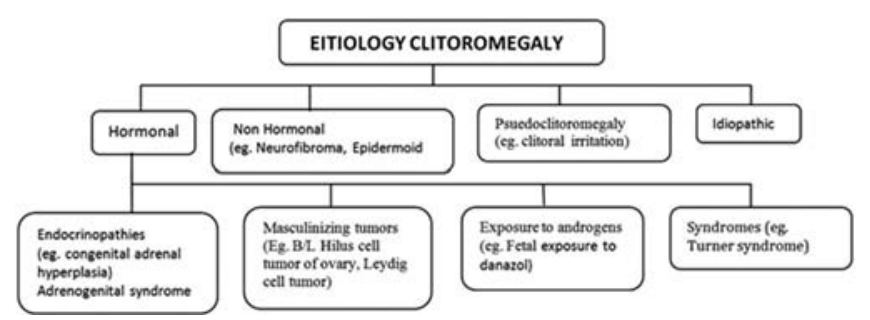

Figure-11: Etiology of Cliteromegaly

as idiopathic. Aesthetic reconstruction surgery helps to relieve psychological stress, and restore normal clitoral morphology without compromising sexual function. Clitoroplasty by preserving the dorsal neurovascular bundle and extensive network of nerves around the corpora can preserve maximum possible sensation to the glans.

\section{Acknowledgment}

We thank Dr Devajyoti Guin for his help in drawings.

\section{Financial support and sponsorship}

Nil.

\section{Conflicts of interest}

There are no conflicts of interest.

\section{REFERENCES}

1. Nigam A, Prakash A, Sarema P, Yadav R, Raghunandan C. Hirsutism and abnormal genitalia. JIACM 2011; 12:46-8.

2. Tuteja N, Saluja S, Jain SK, Yadav A, Agarwal LD, Hooja N. Congenital Idiopathic Isolated Clitoromegaly. Int J App Basic Med Res2014; 4:192-4

3. Acimi S. Clitoroplasty: A variant of the technique. Urology 2008; 72:669-71.

4. Minto CL, Liao LM, Woodhouse CR, Ransley PG, Creighton SM. The effect of clitoral surgery on sexual outcome in individuals who have intersex conditions with ambiguous genitalia: A cross-sectional study. Lancet 2003; 361:1252-7.

5. Copcu E, Aktas A, Sivrioglu N, Copcu O, Oztan Y.Idiopathic isolated clitoromegaly: A report of two cases. Reprod Health2004; 1:4

6. O'Connell HE, Sanjeevan KV, Hutson JM. Anatomy of the clitoris. J Urol 2005; 174:1189-95

7. Senaylı A. Controversies on clitoroplasty. Therapeutic Advances in Urology 2011; 3:273-7.

8. Lean WL, Hutson JM, Deshpande AV, Grover S. Clitoroplasty: Past present and future.PediatrSurgInt2007; 23:289-93.

9. Pippi Salle JL, Braga LP, Macedo N, Rosito N, Bagli D. Corporeal sparing dismembered clitoroplasty: An alternative technique for feminizing genitoplasty. J Urol2007; 178:1796-801. 